\title{
Qualitative Analysis In Financial Studies: Employing Ethnographic Content Analysis
}

\author{
Henry I. Silverman, Roosevelt University, USA
}

\begin{abstract}
To the extent that relevant variables are well-defined or readily observable, empirical studies in finance typically employ classical investigative techniques and positivistic methodologies to measure and analyze financial phenomena. Many unanswered questions in modern finance however, rely critically on insight into the behavior or intentions of various agents, for which there may be no easily discernible proxy that lends itself to traditional quantitative analysis. Alternatively then, Patton (1990) notes that qualitative methods may be employed to discover "what people do, know, think, and feel". A particularly promising qualitative approach, recently introduced into financial studies to discover the encoded investment objectives and activities of fund managers, is Ethnographic Content Analysis (ECA). In this paper, we review the literature on ECA and offer an instructional set on the use of ECA in an analysis of official disclosure documents.
\end{abstract}

Keywords: finance, disclosure documents, qualitative analysis, ethnographic content analysis

\section{INTRODUCTION AND LITERATURE}

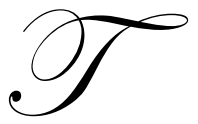

o the extent that relevant variables are well-defined or readily observable, empirical studies in finance typically employ classical investigative techniques and positivistic methodologies to measure and analyze financial phenomena. Many unanswered questions in modern finance however, rely critically on insight into the behavior or intentions of various agents, for which there may be no easily discernible proxy that lends itself to traditional quantitative analysis. Alternatively then, Patton (1990) notes that qualitative methods may be employed to discover "what people do, know, think, and feel".

A particularly promising qualitative approach, recently introduced into financial studies which involve an analysis of official disclosure documents, is Ethnographic Content Analysis (ECA). Silverman (1993) notes that ethnography seeks to understand the organisation of social action in particular settings and Hammersley and Atkinson (1983) argue that as written accounts are an important feature of many settings, ethnographers may take account of documents as a reflection of the setting under investigation. These latter authors cite the extensive use of documents by Gamst (1980) in his study of locomotive engineers, and in research emanating from the early Chicago School. Patton (1990) observes that a particularly rich source of information about many programs derives from records and documents and that "... in contemporary society, all programs leave a trail of paper that the evaluator can follow and use to increase knowledge and understanding about the program". Similarly, Silverman (1993) suggests that public records constitute a "potential goldmine" for investigation in large part because they reveal how agencies account for, and legitimate their activities. research:

Hammersley and Atkinson (1983) offer an enthusiastic endorsement of the use of documents in qualitative

The presence and significance of documentary products provides the ethnographer with a rich vein of analytic topics, as well as a valuable source of information. Such topics include: How are documents written? How are they read? Who writes them? Who reads them? For what purpose? On what occasions? With what outcomes? What is recorded? What is omitted? What is taken for granted? What does the writer seem to take for granted about the reader(s). What do readers need to know in order to make sense of them? 
Altheide (1987) suggests that several aspects of an ethnographic research approach can be applied to document analysis to produce ethnographic content analysis, defined generally as the reflexive analysis of documents (Plummer, 1983). Although Altheide (1987) acknowledges that ECA has been less widely recognized as a distinctive research method, he notes that various facets of the approach are apparent in document analyses by historians, literary scholars, and social scientists. More recently, Altheide (1996) defines ECA as "an integrated method, procedure, and technique for locating, identifying, retrieving, and analyzing documents for their relevance, significance, and meaning", where "the emphasis is on discovery and description, including search for contexts, underlying meanings, patterns, and processes...”. Thematic categories using ECA are established both $a$ priori and through a content analysis of text. Once the researcher has derived categories and a coding system from the ethnographic study data, quantitative content analysis design provides a set of procedures to systematically code the categories with reliability checks to analyse, validate, and report the results (Altheide, 1987; Smith, Sells, and Clevenger, 1994). Within ECA, concept development, sampling, data collection, data coding, data analysis, and interpretation are reflexive (Plummer, 1983; Altheide, 1987).

In an analysis of mutual fund disclosure documents, Silverman (2008) notes that although the creation of a prospectus and annual report typically reflect the efforts of various agents - investment bankers, lawyers, advertising firms - these documents are a product, ultimately, of the investment company offering the mutual fund. As such, prospectuses and annual reports are essentially cultural artifacts (Hodder, 2000) or "patterns of cultural construction" (Chambers, 2000) unique to a specific group of industry professionals. Notwithstanding the fact that the prospectus and annual report are ostensibly written for investors and must meet certain standards by law for readability and intelligibility, these documents may be expected to contain technical terminology, conceptual themes, and language generally, that is idiosyncratic to the investment company and/or to the fund management industry. Thus, meaning and significance (for the outsider) may be obscured, ambiguous, or heavily nuanced. Silverman (2008) consequently suggests that, in an effort to apprehend the often encoded investment objectives and risk-taking of the fund company producing the materials, prospectuses and annual reports are subject to rigorous discovery and interpretive research procedures supporting an ECA approach to analysis.

\section{METHODOLOGY: ANALYZING CORPORATE DISCLOSURE DOCUMENTS WITH ETHNOGRAPHIC CONTENT ANALYSIS}

Official disclosure documents, i.e., mutual fund and IPO prospectuses, quarterly and annual reports filed with the Securities and Exchange Commission, may be examined using ECA in the following manner:

1) Subject materials are initially reviewed by the researcher to enhance familiarity with the basic organizational structure, conceptual framework, and terminology across documents. This process is facilitated by any previous experience with similar documents in a research or professional setting.

2) The literature review and preliminary questions for study facilitate the identification of some general conceptual categories and descriptive themes in the materials, which are noted. Silverman (2008) for example, seeks to identify the investment objectives, strategies and risk-taking of mutual fund managers. Categories provide structure for grouping units of analysis into the same conceptual units that have similar meaning (USGAO, 1989), however as Altheide (1987) points out, "although [certain] categories and variables initially guide the [ECA] study, others are allowed and expected to emerge throughout the study". Thus, ECA is a process of constant discovery and constant comparison of meanings and nuances (Glaser and Strauss, 1967). It is important however, to ensure that caution is employed in relation to how categories are defined and the manner in which patterns of language are assigned to each category to avoid a claim of "forcing" an outcome. With respect to official disclosure documents, this type of control is aided by the legal obligation of the investment house or public company to disclose specific information within the prospectus.

3) Employing a reflexive process, the researcher works across documents in the sample and employs a process of iteration between the data and the emerging classification system. Although ethnographic analysis allows for data to be allocated to more than one category (Hammersley and Atkinson, 1983; Altheide, 1987), ideally, categories will be constructed which ultimately meet the criteria of "internal homogeneity" and "external homogeneity" as set forth by Guba (1978); the former being demonstrated by the fact that the data within each category will dovetail in a meaningful way, and the latter evidenced by clear differences 
between categories, that is, a lack of overlap and duplication. It is practicable however, to establish relationships between categories which enable questions to be refined and to facilitate analysis of the data with quantitative content analysis. Note for example, the potential for association between the categories of investment "objective" and "risk" as defined by Silverman (2008). (See Figure 1).

4) Once the categories and coding system have been derived using ECA, a quantitative content analysis design can provide a set of procedures to code the categories systematically with reliability checks embodied in the framework to analyze, validate and report results (see number 6, below). Final categories and definitions are then derived (Altheide, 1987).

5) As indicated earlier, ethnographic content analysis is used to document and understand the communication of meaning, as well as to verify theoretical relationships (Altheide, 1987). Informed by this approach, the individual data elements in each category are examined within the context of the various theoretical models discussed in the literature review, interpreted, and subsequently subsumed into broader, generalized categories for further analysis.

6) The data generated by the coding system is analyzed using quantitative frequency counts as well as by qualitative narrative data from the text (Smith, Sells, and Clevenger, 1994). Thus, narrative and numeric data are presented concurrently (Altheide, 1985) to support a descriptive interpretation. Validation is supported by the use of examples from the text itself to demonstrate claims (Smith, Sells, and Clevenger, 1994) and may also be achieved via data triangulation (Denzin, 1978). Silverman (2008) for example, pairs and analyzes the mutual fund prospectus and annual report occurring in the same operating year so as to validate findings via an examination of ex ante and ex post narratives.

7) Reliability and validity of results drawn from ethnographic content analysis are enhanced via intercoder reliability (Smith, Sells, and Clevenger, 1994). This procedure is derived from quantitative content analysis such that categories are tested for reproducibility when coders, unaware of the objectives of the study, analyze the same text and identify comparable data categories and elements (Weber, 1990). When high reliability is achieved, the coding rules can be applied to the entire text (Krippendorff, 1980).

Figure 1 ECA Data Categories and Data Elements

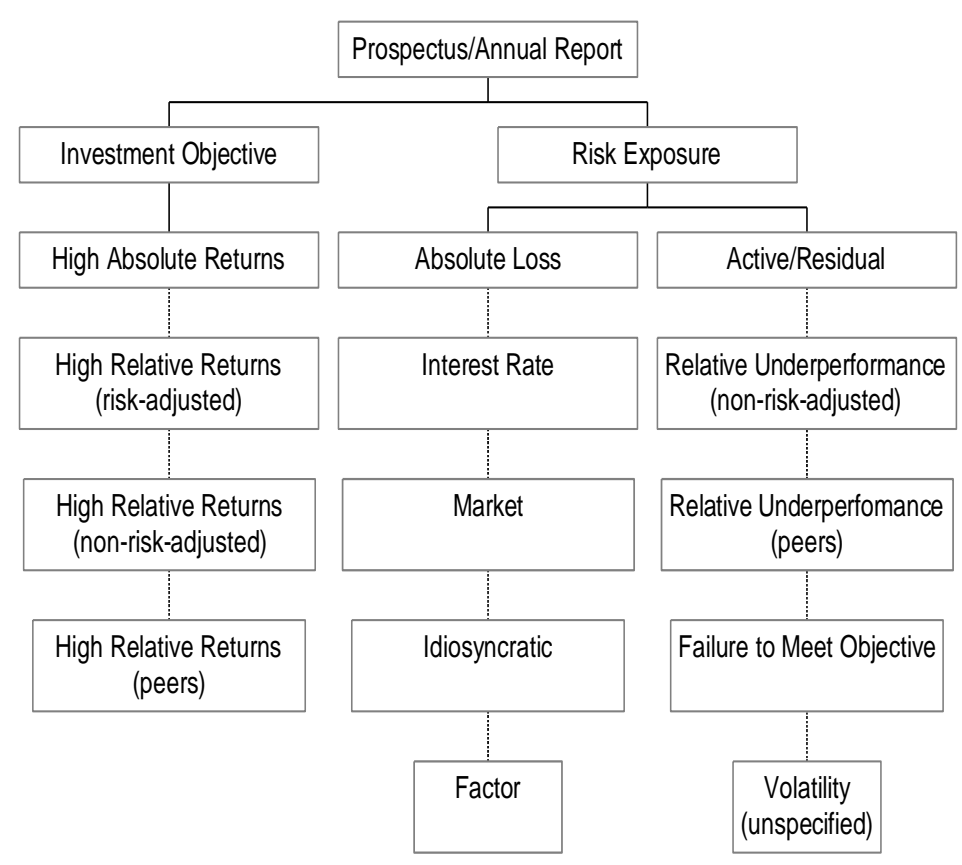

\section{CONCLUSION}

Orthodox financial studies have traditionally relied upon positivistic methodologies to measure and analyze empirical phenomena. Where variables are sometimes less accessible and simultaneously open to greater 
descriptive interpretation, such as studies in the social sciences and media, qualitative approaches like Ethnographic Content Analysis (ECA) have been successfully employed to analyze documents for relevance, significance, and meaning. As demonstrated, ECA can be effectively extended to financial studies where official disclosure documents are examined for the encoded objectives and activities of investment and corporate managers who produce these materials.

\section{AUTHOR INFORMATION}

Henry I. Silverman is an Assistant Professor of Finance at Roosevelt University in Chicago and a director of an asset management firm based in London.

Engaged in research on investment companies, their return objectives, investment strategies, and risk-taking behavior, Dr. Silverman has conducted numerous interviews with US and European fund managers and performed analytic work on their disclosure practices and documents. Dr. Silverman's findings were presented to the Chairman of the British government's Financial Ombudsman Service in 2003.

Dr. Silverman is author of the academic text Theory and Practice of Fund Management and a member of the CFA Institute.

\section{REFERENCES}

1. Altheide, David L. "Format and Ideology in TV News Coverage of Iran". Journalism Quarterly, 62 (1985): 346-351.

2. Altheide, David L. "Ethnographic Content Analysis". Qualititative Sociology, 10(1) (Spring, 1987): 6577.

3. $\quad$ Altheide, David L. Qualitative Media Analysis. Newbury Park, CA: Sage, 1996.

4. Chambers, Erve. “Applied Ethnography” in N. Denzin \& Y. Lincoln (eds.), Handbook of Qualitative Research, $\left(2^{\text {nd }}\right.$ ed.). Thousand Oaks, CA: Sage, 2000.

5. $\quad$ Denzin, N.K. The Research Act: A Theoretical Introduction to Sociological Methods. New York: McGraw-Hill, 1978.

6. Gamst, Frederick. The Hoghead: An Industrial Ethnology of the Locomotive Engineer, New York: Holt Rinehart and Winston, 1980.

7. Glaser, B.G. and A.L. Strauss. The Discovery of Grounded Theory: Strategies for Qualitative Research. New York: Aldine, 1967.

8. Guba, E. G. Toward a Methodology of Naturalistic Inquiry in Educational Evaluation. Monograph 8. Los Angeles: UCLA Center for the Study of Evaluation, 1978.

9. Hammersley, Martin and Paul Atkinson. Ethnography: Principles in Practice, Tavistock Publications, 1983.

10. Hodder, I. "The Interpretation of Documents and Material Culture" in N. Denzin \& Y. Lincoln (eds.), Handbook of Qualitative Research, ( $2^{\text {nd }}$ ed.). Thousand Oaks, CA: Sage, 2000.

11. Krippendorff, K. Content Analysis: An Introduction to Its Methodology. Newbury Park, CA: Sage, 1980.

12. Patton, Michael Quinn. Qualitative Evaluation and Research Methods. Thousand Oaks, London, New Delhi: Sage, 1990.

13. Plummer, Ken. Documents of Life: An Introduction to the Problems and Literature of a Humanistic Method. London: George Allen \& Unwin, 1983.

14. Silverman, David. Interpreting Qualitative Data: Methods for Analysing Talk, Text and Interaction. London: Sage, 1993.

15. Silverman, Henry I. "Mutual Fund Risk-Return Profiles: A Novel Use of Triangulation". Journal of Risk Management in Financial Institutions, 1(2), (2008): 191-222.

16. Smith, T, S. Sells, and Clevenger. "Ethnographic Content Analysis of Couple and Therapist Perceptions in a Reflective Team Setting", Journal of Marital and Family Therapy, 20(3), (1994): 267-286.

17. United States General Accounting Office. "Content Analysis: A Methodology for Structuring and Analyzing Written Materials.” USGAO Publication No. 10.1.1. Gaithersburg, Maryland: U.S. Government Printing Office.

18. Weber, R. P. Basic Content Analysis, (2nd ed.). Newbury Park, CA: Sage, 1990. 